\title{
OBITUARY
}

\section{CARL v. HESS}

The death of Carl v. Hess, director of the Munich Eye Klinik, has already been announced in the columns of this Journal for September. He died on June 28, 1923, at the age of sixty years, from acute pernicious anaemia, following an operation not serious in itself. Thus passed away a great scientist, an acute observer, and a loyal and genial friend. He was the only son of Wilhelm Hess, the well-known ophthalmologist, a close friend of Albrecht v. Graefe, and for many years secretary of the Heidelberg Ophthalmological Society. Great pains were taken with the early education of Carl, and especial attention was paid to the acquisition of foreign languages, in which he became remarkably proficient. Carl v. Hess acted as assistant to Hering, the physiologist, and to Sattler, the ophthalmologist, both of Prague, and as might be expected from this conjunction $v$. Hess became the happiest combination of physiologist and ophthalmologist that it is possible to imagine. He studied also in Heidelberg, Bonn, and Strasburg. For a short time he assisted in the Schoeler Klinik in Berlin. In 1891 he was first assistant and Privatdozent in the University Eye Klinik of Leipzig. In 1896 he was appointed extraordinary professor as successor to Uhthoff and nominated ordinary professor and director of the University Eye Klinik in Marburg. Shortly after this he was awarded for his work upon accommodation the von Welz-Graefe Prize by The Heidelberg Congress. As successor to $\mathrm{J}$. von Michel, in 1900 he was called to Würzburg, where he lived for twelve years, and may be said to have reached the summit of his career. During this period he wrote his two famous textbooks, namely, "Anomalies of Refraction and Accommodation" and "The Pathology and Therapy of the Lens System," and published most of his investigations on the light and colour sense, as well as treatises dealing with comparative accommodation. It is of interest to recall the fact that in pursuit of his favourite studies he passed nearly every spring at the Zoological Station! at Naples. In 1912 he was called to Munich as successor to Eversbuch. In 1922 the German Ophthalmological Society presented v. Hess with the Graefe Medal, the highest distinction within its gift, and this gave Hess the greatest pleasure, since only men of the calibre of Leber, Helmholtz and Hering had been its recipients. During the last ten years of his life Hess was incessantly engaged with the problems of human colour blindness, although he had begun to work at colour when with Hering, who adopted, indeed, some of his views.

A most sympathetic appreciation of Hess, written by his friend 
and colleague, Professor K. Wessely, of Würzburg, appears in the August number of the Archiv für Augenheilkunde, a periodical with which Hess was connected in an editorial capacity for nearly twenty years.

\section{NOTES}

Committee of A Committee of the Department of Scientitic Scientific and Industrial and Industrial Research has been appointed: Research

(a) to consider and advise on requests from other departments for investigations in connection with the lighting of buildings and allied problems, and to supervise such investigations if approved by the Advisory Council: (b) to cooperate with the Medical Research Council by making arrangements for and supervising physical investigations needed in connection with physiological researches on illumination; $(c)$ to examine the need for general researches on illumination, to make such recommendations to the Advisory Council as they may consider desirable, and to undertake the supervision of approved investigations. The constitution of the Committee is as follows:-Mr. C. C. Paterson, General Electric Company (Chairman); Sir John Parsons, Mr. D. R. Wilson, and Dr. H. Hartridge, Medical Research Council; Mr. J. W. T. Walsh, National Physical Laboratory; Mr. L. Gaster, Illuminating Engineering Society; Dr. J. S. G. Thomas, South Metropolitan Gas Company ; Messrs. Alban Scott and S. B. Russell, Architects. Mr. S. C. Bromley (Secretary).

Bijapur Branch of the WE have received a copy of the third Annual Bombay Presidency Report (1922) of the Bijapur Branch of the Blind Relief Assoctation Bombay Presidency Blind Relief Association. This Association, whose aim is to carry out measures for the "prevention and relief of blindness," is doing excellent work among the poor native population, and especially among the children. Its efforts for the prevention of blindness are especially praiseworthy. 